\title{
Fusarium oxysporum colonizes the stem of resistant tomato plants, the extent varying with the R-gene present
}

\author{
H. C. van der Does - M. E. Constantin - P. M. Houterman • F. L. W. Takken • \\ B. J. C. Cornelissen - M. A. Haring - H. A. van den Burg • M. Rep
}

Accepted: 26 August 2018 / Published online: 1 September 2018

(C) The Author(s) 2018

\begin{abstract}
The plant immune system employs resistance $(R)$ genes to detect the presence of pathogenic microbes by the avirulence (Avr) factors they produce. Whereas some $R$-genes confer extreme resistance, completely blocking pathogen proliferation, others act later during infection and allow initial microbial multiplication in the host. We hypothesized that transmembrane R-proteins as opposed to intracellular R-proteins - may recognize and arrest pathogen entry earlier in the infection process. In tomato, two transmembrane R-proteins (I and I-3) and one intracellular R-protein (I-2) have been identified conferring resistance against the same pathogen: the soil borne fungus Fusarium oxysporum f.sp. lycopersici (Fol). We found that in all root inoculations with Fol on resistant tomato plants, the fungus was able to reach the vasculature of the stem. However, the extent of host vasculature colonization was less than that in susceptible plants. This indicates that a complete blockade of
\end{abstract}

Electronic supplementary material The online version of this article (https://doi.org/10.1007/s10658-018-1596-3) contains supplementary material, which is available to authorized users.

H. C. van der Does • M. E. Constantin • P. M. Houterman • F. L. W. Takken • B. J. C. Cornelissen · H. A. van den Burg • M. Rep $(\bowtie)$

Molecular Plant Pathology, Swammerdam Institute for Life Sciences, University of Amsterdam, Science Park 904, 1098XH Amsterdam, The Netherlands e-mail: m.rep@uva.nl

M. A. Haring

Plant Physiology, Swammerdam Institute of Life Sciences, University of Amsterdam, Science Park 904, 1098XH Amsterdam, The Netherlands fungal ingress does not occur in any of the incompatible interactions. However, resistance mediated by the intracellular R-protein I-2 allowed more extensive fungal colonization than resistance mediated by the transmembrane R-proteins I or I-3. The first phases of invasion - penetration of the root epidermis, cortex colonization and early stage xylem colonization - are unaffected by $R$-gene mediated resistance of the host. We suggest that all 3 R-proteins only limit Fol colonization after the fungus has reached the xylem tissues, and that I and I3 act prior to and/or are more effective than I-2 in reducing pathogen proliferation and spread.

Keywords Johanna Westerdijk legacy · Fusarium oxysporum $\cdot$ Wilt disease $\cdot$ Disease resistance $\cdot$ Xylem colonization $\cdot$ Resistance genes

\section{Introduction}

Plants are continuously subject to invasion attempts by microbes and contain a complex immune system that protects them against deleterious effects of microbial invasion. So-called resistance $(R)$ genes determine the specificity of the plant immune system. The presence of an $R$-gene can make the difference between a heavily diseased and a completely healthy plant. $R$-genes encode receptor proteins that enable recognition of pathogenic microbes and typically recognize - directly or indirectly - a protein that is secreted by the microbe during infection. Such a pathogen-derived protein is referred to as an avirulence (Avr) protein and is encoded 
by an $A V R$-gene. The interaction between $R$-genes and $A V R$-genes is described by the gene-for-gene hypothesis (Jones and Dangl 2006; Keen 1990).

Upon recognition of an Avr protein, the R-protein activates plant defense responses leading to resistance. Interestingly, a successful resistance response (incompatibility) does not always lead to extermination of the pathogen. The extent to which a fungal pathogen can colonize its host in an incompatible interaction (i.e. a resistant plant) varies greatly. In some cases, the plant resistance response is very rapid and effective, limiting spread of the pathogen within micrometers. This is the case, for example, in the apoplastic interaction between Cladosporium fulvum and tomato (De Wit et al. 1985). In other cases, however, resistant plants are colonized over centimeters by the pathogen, even though they are outwardly indistinguishable from un-inoculated plants. This is, for example, observed in interactions between resistant tomato varieties and Verticillium dahliae or $\mathrm{Fu}$ sarium oxysporum, where the pathogen spreads from the roots to the stem before being stopped (Mes et al. 2000; Fradin et al. 2009). Various bacterial pathogens can also proliferate inside a resistant host and increase bacterial counts multiple orders of magnitude before being contained. Examples of this are Xanthomonas oryzae pv. oryzae (Xoo) infecting rice and Ralstonia colonizing tomato (Deslandes et al. 2002; Deslandes et al. 1998; Pruitt et al. 2015; Yoshimura et al. 1998).

It is unclear what causes these large differences in colonization of resistant plants. We hypothesized that transmembrane R-proteins perceiving the Avr protein outside the host cell mount a different response than R-proteins that detect their Avr intracellularly, resulting in differences in host colonization by the pathogen. To properly compare the efficacy of transmembrane R-proteins and intracellular R-proteins, it is crucial to use the same pathosystem for both types of R-protein. To date, only two such pathosystems have been identified: in rice against the bacterium Xoo (R-proteins Xa1 and Xa21) (Yoshimura et al. 1998; Pruitt et al. 2015) and in tomato against the fungus $F$. oxysporum f.sp. lycopersici (Fol) (R-proteins I, I-2 and I-3) (F. Takken and Rep 2010; Catanzariti et al. 2015; Catanzariti et al. 2017; Simons et al. 1998; Huang and Lindhout 1997). In this study, we use the Fol - tomato patho-system to determine the differences in permitted colonization mediated by extra- or intracellular Avr perception.
F. oxysporum is a soil-borne fungus that infects plants via the roots and colonizes the xylem vessels. $F$. oxysporum infection causes wilt symptoms, similar to those of other xylem colonizing fungi like Ophiostoma ulmi, the causal agent of Dutch Elm disease (Tchernoff 1965; Westerdijk et al. 1931). In the interaction between Fol and tomato, several $R$-gene - AVRgene combinations have been identified (Table 1). Three of these $R$-genes (I, $I-2$ and $I-3$ ) have been introgressed from wild tomato relatives into commercial cultivars and confer protection against Fol race 1 strains (carrying $A V R 1, A V R 2$ and $A V R 3$ ), Fol race 2 strains (lost AVR1, carrying $A V R 2$ and $A V R 3$ ) and - up till now - Fol race 3 strains (lost $A V R 1$, mutated AVR2 and carrying AVR3), respectively (F. Takken and Rep 2010; Catanzariti et al. 2015; Catanzariti et al. 2017; Simons et al. 1998; Huang and Lindhout 1997). The corresponding Avr proteins (Avr1, Avr2 and Avr3) - originally identified as Six4, Six 3 and Six1, respectively - are small proteins that are secreted by Fol during host colonization. Both Avr2 and Avr3 are required for full virulence on susceptible plants (Rep et al. 2004; Houterman et al. 2009; Houterman et al. 2007; Houterman et al. 2008).

In addition to the abovementioned $I$-genes, two more Fol resistance genes have been identified: $I-1$ that also recognizes $A V R I$, and $I-7$ of which the Avr has not yet been identified (Sarfatti et al. 1991; Gonzalez-Cendales et al. 2016). Of the $R$-genes that protect tomato against Fol, $I-2$ is the best characterized. I-2 encodes a typical intracellular NLR-type immune receptor that contains a central NB-ARC domain and a C-terminal LRR domain (Simons et al. 1998). The $I-2$ gene is mostly expressed in the vascular tissue, which could explain why the fungus reaches the vasculature in an incompatible interaction (Mes et al. 2000). Avr2 is translocated into the host cells during infection after which recognition by I-2 depends on nuclear localization of Avr2 (Houterman et al. 2009; Di et al. 2016). In contrast to $I-2$ the other cloned $R$-genes encode membrane-spanning receptors. I is a receptor-like protein with an extracellular LRR domain (LRR-RLP), I-3 is a S-receptor like kinase (SRLK), with an extracellular G-type lectin domain, a cysteine rich PAN/APPLE domain and an intracellular kinase domain, and I-7 is a receptor like protein (RLP) (Catanzariti et al. 2017; Gonzalez-Cendales et al. 2016; Catanzariti et al. 2015). Interestingly, Avr1 can suppress both I-2- and I-3-mediated resistance (Rep et al. 2005; Houterman et al. 2008). 


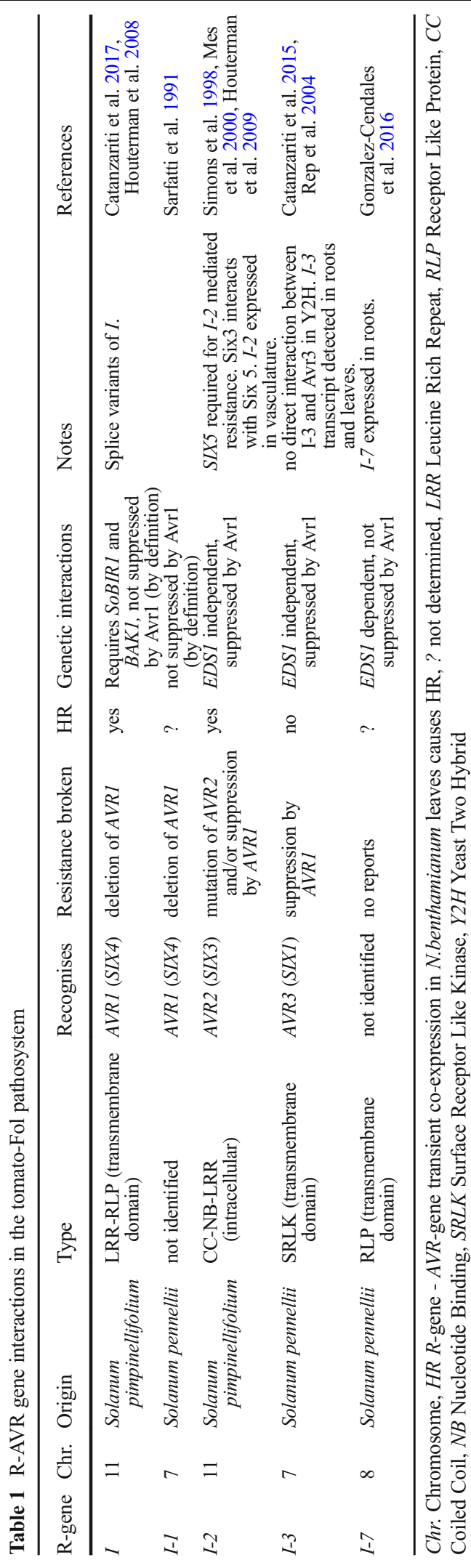

We tested whether in the tomato-Fol pathosystem resistance conferred by transmembrane R-proteins (i.e. extracellular Avr perception) results in a different level of host colonization than resistance conferred by Rproteins that detect their Avr intracellularly. We observed that plants with immune responses mediated by the extracellular immune receptors I and I-3 are more effective in restricting fungal spread than those mediated by the intracellular immune receptor I-2. In addition, Fol was found to colonize both root and stem xylem tissue in resistant plants suggesting that Fol may be considered an endophyte on a resistant plant genotype: it colonizes the host but does not cause disease.

\section{Materials and methods}

Plant inoculations

To test fungal colonization, either 4-week-old tomato plants or 10-day-old tomato seedlings were inoculated via the root dip method (Mes et al. 1999; Wellman 1939). Briefly, spores were isolated from 3 to 5 dayold liquid cultures grown in minimal medium (1\% $\mathrm{KNO}_{3}, 3 \%$ sucrose and $0.17 \%$ Yeast Nitrogen Base without amino acids and ammonia, grown at $25{ }^{\circ} \mathrm{C}$, $175 \mathrm{rpm})$. Spores were diluted in tap water to $10^{7}$ spores $/ \mathrm{ml}$. Plants or seedlings were taken out of the soil, their root systems trimmed to damage the main root, to obtain a more uniform and homogeneous infection, and dipped in the spore suspension for about $1 \mathrm{~min}$. Plants or seedlings were repotted in soil and grown in a greenhouse at $25{ }^{\circ} \mathrm{C}, 65 \%$ humidity and $16 \mathrm{~h}$ light/day. Fungal colonization was determined 9,20 or 21 days after infection.

For microscopy, seedlings were treated as described in (van der Does et al. 2008), 10-day-old tomato seedlings were taken carefully from the potting soil in which they were sown and the root system was washed gently in tap water to remove the soil. Clean plantlets were placed in Petri dishes, with the roots spread out on the bottom of the dish and the hypocotyl leaning to the vertical wall, the cotelydons and leaves sticking outside the Petri dish. The dish was filled with $25 \mathrm{ml}$ water to which Fol spores were added to a final concentration of $0.5 \times 10^{7}$ spores $/ \mathrm{ml}$. Holes in the lid allowed the Petri dish to be closed (to minimize evaporation) with the top parts of the plant sticking out. Plantlets were inspected microscopically 2-4 days after inoculation. 
Fungal outgrowth assays

Plants were prepared as follows: of 7-week-oldtomato plants the distances between the leaves and soil surface were measured (in $\mathrm{cm}$ ) and at each leaf level a stem sample was taken. 19-day-old tomato plants (infected as seedling) were cut at soil level and leaves were removed, leaving part of the petiole attached. Then, stem pieces or entire seedlings were surface sterilized by submergence in $70 \%$ ethanol and washed by submergence in sterile water. A slice of each sterilized stem piece was put on plate made of Potato Dextrose Agar-PDA, supplemented with $200 \mathrm{mg} / \mathrm{L}$ streptomycin and $100 \mathrm{mg} / \mathrm{L}$ penicillin to reduce bacterial growth. The small plants (19 days old) were cut into pieces of around $8 \mathrm{~mm}$ long, and each piece was put onto PDA plates supplemented with streptomycin and penicillin. After two to 3 days of incubation in the dark at $25{ }^{\circ} \mathrm{C}$ fungal outgrowth was scored. Fungal colonization levels were determined as the maximum distance from the soil until which fungal outgrowth was detected (in $\mathrm{cm}$ ). In the 2017 experiment, 10 (19-day-old) plants were used per condition. In the 2014 experiment, six (19-day-old) plants were used per condition. In the fungal colonization assay on older plants ( 7 weeks) 13 plants were used per condition. The assay on older plants was performed yearly between 2011 and 2017, as part of a practical course in the Biology bachelor program of the University of Amsterdam. For all outgrowth experiments, the bar graphs were created from the average height above soil level until where Fol was detected (so an average of 6,10 or 13 plants) plus the average height of the plants. Error bars indicate the standard deviation (SD).

Fungal transformation

The creation of the $\mathrm{P}_{\mathrm{SIX} 1}:: \mathrm{GFP}$ construct in pPZP200, a binary vector for Agrobacterium-mediated transformation of Fusarium (Hajdukiewicz et al. 1994) is described in (van der Does et al. 2008). Agrobacterium-mediated Fusarium transformation of Fol004, Fol007 and Fol029 with pPZP200-P $\mathrm{SIX1}_{1}:$ GFP was performed as described in (F. L. Takken et al. 2004). Transformants were selected on zeocin $(100 \mu \mathrm{g} / \mathrm{ml}$, plates buffered with $0.1 \mathrm{M}$ Tris $\mathrm{pH} 8$ ) and monospored before further application.
Microscopy

Microscopic imaging was done with the AMG Evos FL digital inverted microscope equipped with a GFP (470/ 22 to $510 / 42 \mathrm{~nm}$ ) light cubes, and driven by built-in software for image acquisition. Images were captured with $10 \times 10$ and $10 \times 20$ magnification.

\section{Results}

I-2-mediated immunity allows partial colonization of the host xylem

During infection Fol colonizes the xylem vessels of tomato. The $I-2$ gene is expressed in the tissue surrounding the xylem vessels and it has been reported that Fol is able to reach the xylem vessels of $I-2$ resistant plants (Mes et al. 2000), but the extent of colonization was not determined.

To determine to what degree Fol can colonize the stem of resistant and susceptible plants we inoculated roots of 4-week-old susceptible (line KG52201) and resistant (line KG324, carrying the $I$ - $2 R$-gene) tomato plants with Fol race 2 strain Fol007 (Mes et al. 2000). Race 2 strains secrete Avr2, triggering I-2mediated resistance (Houterman et al. 2009). 3 weeks after inoculation, susceptible tomato plants had developed severe disease symptoms (wilting and yellowing of the leaves, reduced height and formation of adventitious roots), whereas the resistant plants where indistinguishable from the mockinfected control plants, in line with earlier reports (Rep et al. 2002; Krasikov et al. 2011). To assess fungal colonization, stem slices were taken at regular intervals, surface sterilized with $70 \%$ ethanol, washed with sterile water and placed on agar plates. Fungal outgrowth from the collected stem pieces was scored after 2 days of incubation at $25{ }^{\circ} \mathrm{C}$.

In the compatible interaction, fungal colonization was observed to an average height of up to $12 \mathrm{~cm}$ from the ground. In the case of $I-2$ mediated incompatibility extensive fungal colonization was observed up to $9 \mathrm{~cm}$ on average (Fig. 1). However, since the resistant plants were much taller than the diseased susceptible plants, relative colonization was much lower in resistant plants (20\% of the total height) than in susceptible plants (60\%) (Fig. 1). 

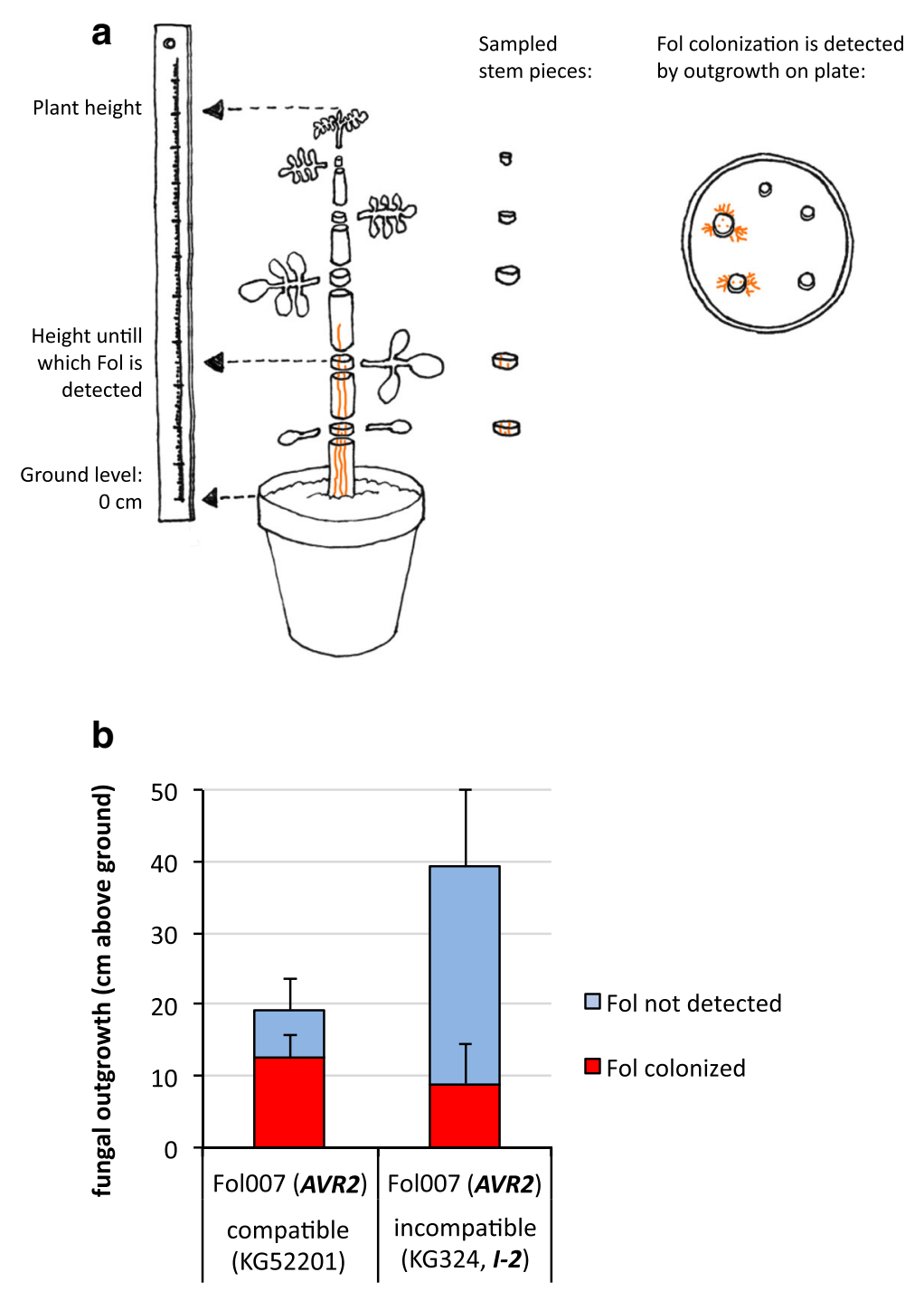

Fig. 1 In $I-2$ resistant tomato plants, Fol colonizes the stem, although not to the same height as in susceptible plants. a Experimental set up to determine the height of Fol colonization in tomato. Fol is depicted in orange. Of inoculated tomato plants stem samples were taken at regular intervals. The distance between each sample and the soil surface was measured (in $\mathrm{cm}$ ). Stem pieces were surface sterilized, put on plate and after incubation of two to 3 days at $25{ }^{\circ} \mathrm{C}$ fungal outgrowth was scored. Fungal colonization levels were determined as the maximum distance

Plants expressing transmembrane R-proteins I and I-3 allow less extensive xylem colonization than plants expressing the intracellular R-protein I-2

Having established that the intracellular R-protein I-2, while providing resistance, allows Fol to colonize the stem, we investigated whether resistance mediated by the transmembrane R-proteins I and I-3 also allows from the soil until which fungal outgrowth was detected (in $\mathrm{cm}$ ). b Fungal colonization of the stem in susceptible (line KG5221 (Mes et al. 1999)) and resistant (line KG324 (Mes et al. 1999), carrying the $I-2 R$-gene) tomato plants, 4 weeks after inoculation of the roots with Fol007 (race 2, producing Avr2). Fungal outgrowth from surface sterilized stem samples taken from different positions in the plant was scored. The bars indicate averages of 13 plants (per treatment). Error bars indicate SD. The experiment was repeated another 6 times, each time with similar results

xylem colonization by Fol. To facilitate comparisons between compatible and incompatible interactions, we inoculated seedlings and scored fungal colonization at the onset of symptom development: 9 days post inoculation (dpi), when size differences between plants are still small (Fig. 2a, Sup Figs 1 \& 2).

To compare fungal colonization levels between $I-, I-$ 2- and $I$-3-mediated resistance, three different Fol strains 


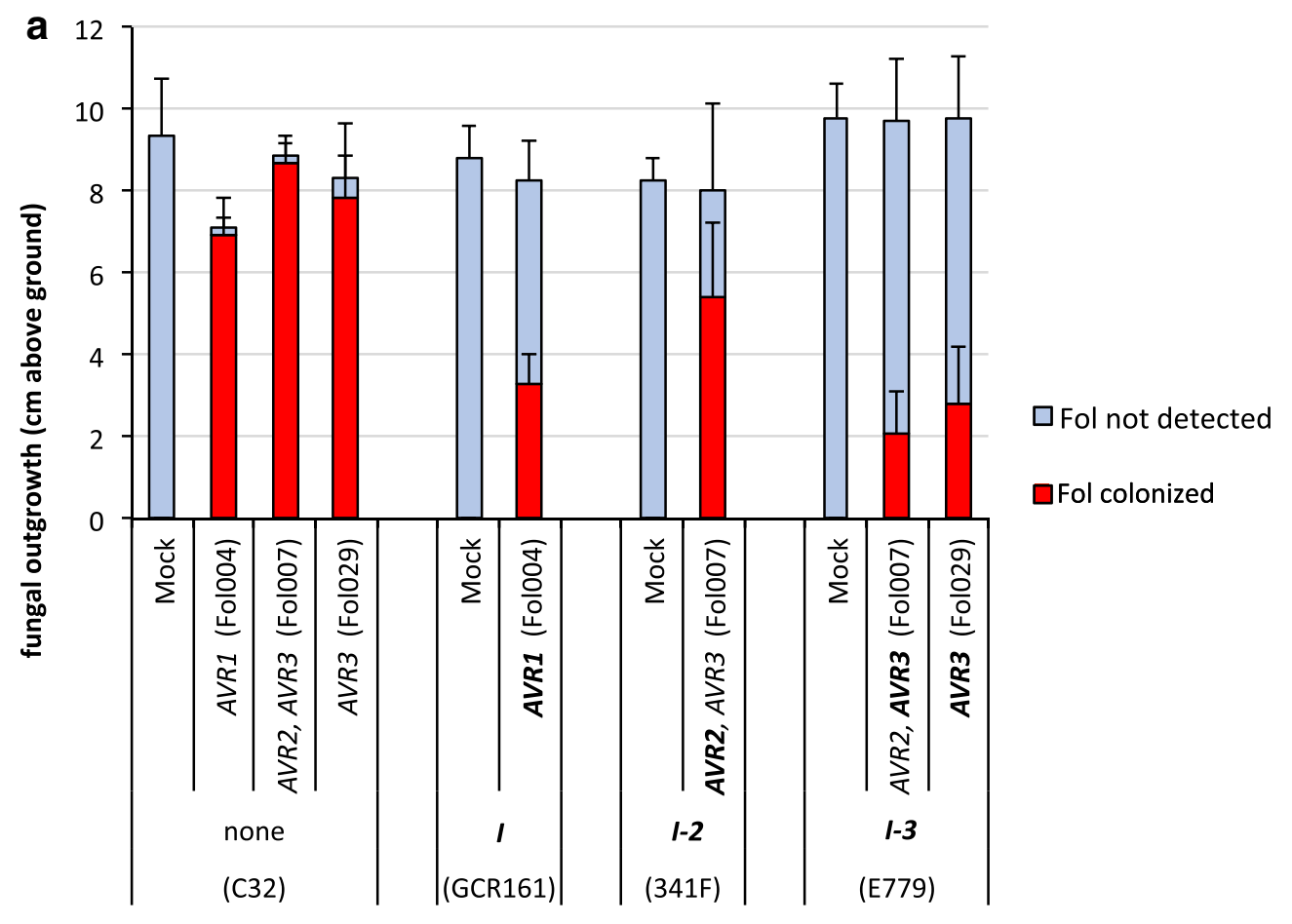

b

Genetic interactions between the tomato lines and Fol strains used in this study

\begin{tabular}{|c|c|c|c|c|c|}
\hline Fol strain (race): & $\begin{array}{l}\text { (tomato cultivar): } \\
\text { AVR genes: }\end{array}$ & $\begin{array}{c}\text { (KG52201 } \\
\text { or C32) } \\
-\end{array}$ & $\begin{array}{c}\text { (GCR161) } \\
I\end{array}$ & $\begin{array}{c}\text { (KG324 or } \\
341 F) \\
\text { I-2 }\end{array}$ & $\begin{array}{c}\text { (E779) } \\
I-3\end{array}$ \\
\hline Fol 004 (race 1) & AVR1, AVR2, AVR3 & $\mathrm{C}$ & 1 & supp. $\mathrm{R}$ & supp. $R$ \\
\hline Fol 007 (race 2) & $(-), A V R 2, A V R 3$ & C & C & 1 & 1 \\
\hline Fol 029 (race 3) & $(-)$, avr2, AVR3 & C & C & C & I \\
\hline
\end{tabular}

C: compatible interaction, susceptibility, severe disease symptoms

I: Incompatible interaction, resistance, no disease symptoms

supp. $R$ : resistance is partially suppressed by AVR1, mild symptoms

avr2: mutated form of $A V R 2$, not recognized

Fig. 2 In resistant tomato seedlings, Fol can colonize the xylem vessels, but less extensive in plants protected by $I$ or I-3 mediated resistance than by $I-2$ mediated resistance. a Stem colonization was determined in Fol inoculated seedlings carrying $I$ (GCR161), I-2 (341F), I-3 (E779), or no known resistance genes against Fol (C32). Seedlings were inoculated with Fol isolates Fol004 (AVR1), Fol007 (AVR2 and $A V R 3)$ or Fol029 (AVR3) or mock inoculated and fungal outgrowth from stem sections was determined $9 \mathrm{dpi}$. Incompatible interactions are indicated with the responsible $R$-gene (' $I$ ' $I$-mediated resistance, ' $I-2$ ' $I$-2-mediated resistance or ' $I-3$ ' $I-3$-mediated resistance). The bars represent the average of 10 plantlets (per treatment). The experiment was performed twice with similar results (for both complete experiments, see Sup Fig. 1). Error bars indicate SD. b Interactions between the tomato lines and Fol strains used in this study: compatibility, incompatibility or suppressed resistance (intermediate phenotype) (Houterman et al. 2008) 
(with different Avr combinations, Fig. 2b) were inoculated on susceptible tomato plants (C32) and one or more Moneymaker-like tomato lines, each carrying one of the $3 R$-genes: I (GCR161), I-2 (341F) and I-3 (E779) (Table 1). In this way, we could compare one interaction comprising $I$-mediated resistance (Fol004 on GCR161) with one encompassing I-2 mediated resistance (Fol007 on 341F) and two interactions covering $I-3$ mediated resistance (Fol007 or Fol029 on E779).

The plants protected by $I-2$ mediated resistance were colonized by Fol up to half of their height, whereas susceptible plants were colonized almost completely $(\geq$ 95\%) (Fig. 2a). In the plants with $I$ or $I-3$ mediated resistance the stem was also colonized by Fol, but to a significantly lower height than observed in plants exhibiting $I-2$ mediated resistance (T-test, $p<0.05$ ) (Fig. 2a). These comparisons show that the plants with $I$ - and $I$-3-resistance are more effective in limiting fungal growth.

Resistance mediated by I, I-2 and/or I-3 does not differ qualitatively during early root colonization

Given the extent of colonization of the stems of resistant plants, it seems that resistance mediated by all of the $3 R$ - genes ( $I, I-2$ and $I-3)$ limits growth in the xylem tissues, rather than preventing entry of the fungus. To investigate whether initial stages of Fol infection (root penetration, cortex colonization and early xylem colonization) are affected by these $R$-genes we monitored root colonization during the first 4 days after inoculation.

To facilitate visualization of the infection process different Fol strains (comprising the different races) were tagged with the fluorescent marker protein GFP. The SIX1 promoter was used to drive GFP expression, because this promoter is only active during colonization of plant tissue (van der Does et al. 2008). The $P_{S I X 1}: \because G F P$ construct was randomly integrated in the genomes and for each Fol race one transformant was selected that showed strong GFP fluorescence inside plant tissues and little or no fluorescence when cultivated outside the plant (not even when growing on the root surface).

For all transformants, clear examples of root penetration, cortex colonization and early xylem colonization were observed on susceptible plants (Fig. 3). Some of the strains had slightly thinner and less fluorescent hyphae, which followed the creases between the tomato cells on the root surface. No clear differences could be observed between the colonization of susceptible or resistant plants that could be attributed to a specific $R$ gene $-A V R$-gene combination or plant line (Fig. 3).

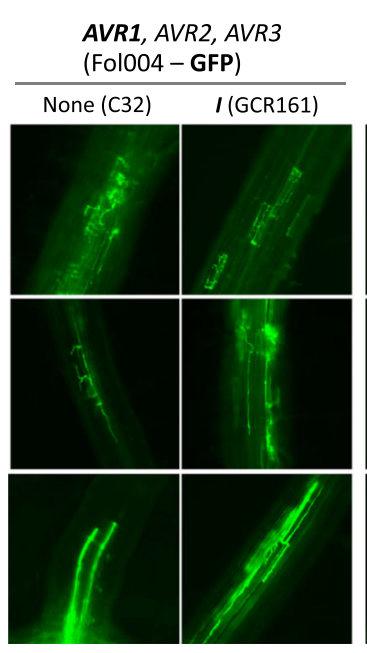

Compatible interaction

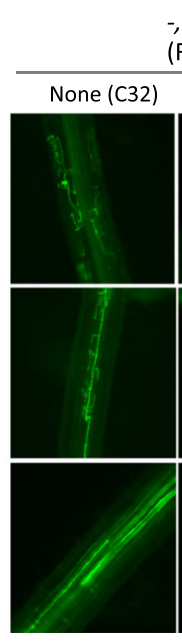

Compatible interaction
-, AVR2, AVR3 (Fol007 - GFP)

I2 (341F)
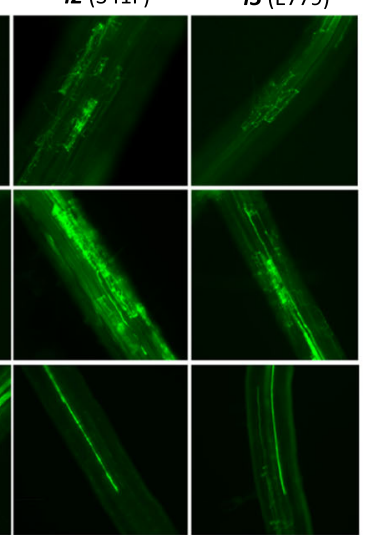

I2-mediated I3-mediated incompatibility incompatibility

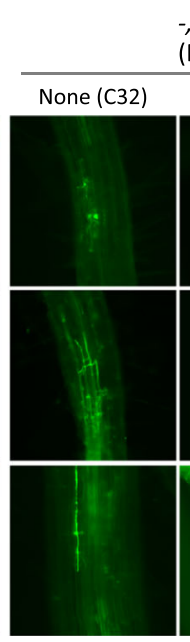

Compatible interaction
-, avr2, AVR3

(Fol029 - GFP)

I (GCR161)

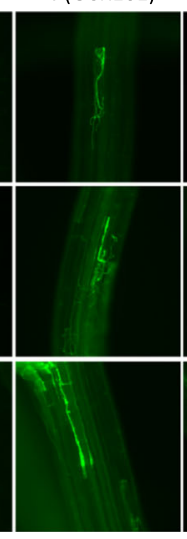

Compatible interaction
Fol007 WT

I3 (E779)

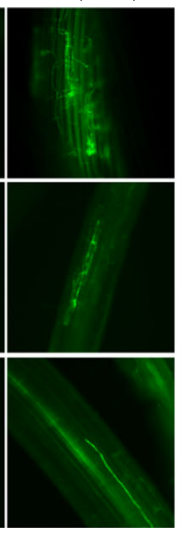

I3-mediated incompatibility
No GFP signal, only root autofluorescence

None (C32)

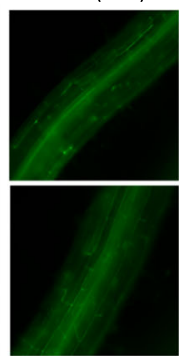

Compatible interaction
Fig. 3 Early tomato root colonization by Fol is not qualitatively affected by $I, I-2$ and/or $I-3$ mediated resistance. Fol-inoculated seedlings carrying I (GCR161), I-2 (341F), I-3 (E779), or no resistance gene against Fol (C32) were inoculated with GFPlabeled Fol isolates Fol004 (AVR1), Fol007 (AVR2, AVR3) or
Fol029 (AVR3). Root colonization was visualized 2-4 dpi on an EVOS fluorescence microscope with a GFP filter. In the Fol strains GFP expression is driven from the $S I X 1$ promoter, which is only active inside plant tissues 
Taken together, these data show that in the tomato Fol interaction $R$-gene mediated resistance allows colonization of the root and subsequently the stem. It also shows that in plants with different $R$-genes, host colonization is contained at different levels. We suggest that all $3 R$-genes (I, $I$-2 and $I-3)$ provide vascular resistance, and that $I$ and $I-3$ do so more effectively than $I-2$.

\section{Discussion}

We report that in the Fol-tomato interaction the first phases of infection - penetration of the root epidermis, cortex colonization and early stage xylem colonizationare unaffected by the presence of any of the $3 R$-genes $I$, $I-2$ or $I-3$, showing that resistance to Fol is a relatively late event following host infection. In all incompatible interactions tested, Fol was able to colonize the stem, although to a lesser extent than in susceptible plants. Plants relying on resistance mediated by the intracellular R-protein I-2 showed less restriction of fungal colonization than plants exhibiting resistance conferred by the transmembrane R-proteins I or I-3.

Tomato patho-systems vary greatly in the extent of pathogen colonization. Spread of the fungal leaf pathogen C. fulvum in resistant tomato leaves is limited to a few micrometers (De Wit et al. 1985), whereas the xylem colonizing fungus Verticillium dahliae - like Fol - spreads from the roots to the stem before being halted (Mes et al. 2000; Fradin et al. 2009). Also the xylem colonizing bacterium Ralstonia proliferates inside resistant tomato plants and bacterial counts shows multiple orders of magnitude increase before the pathogens is contained (Deslandes et al. 2002; Deslandes et al. 1998; Pruitt et al. 2015; Yoshimura et al. 1998).

Resistance to F. oxysporum in different plant species has been extensively studied. Several reports show that F. oxysporum strains are able to colonize the interior of the plant despite the presence of a functional resistance response. For example, in incompatible interactions with common bean $F$. oxysporum strains colonize the plant up to the basal region of the stem (Garces-Fiallos et al. 2017; Buruchara and Camacho 2000), whereas F. oxysporum colonization of resistant pea or watermelon is restricted to the roots and sometimes the crown (Bani et al. 2012; Lu et al. 2014).

Different wheat cultivars exhibit different levels of resistance against $F$. graminearum another important plant pathogen in the genus Fusarium. Resistance is usually classified into two major types, type I against initial penetration and type II against fungal spread within spikes (Pritsch et al. 2000). Rather than conferred by single $R$-genes, this resistance is poly- or oligo-genic and different loci contribute quantitatively to resistance (Zhao et al. 2018; Lin et al. 2006; Xue et al. 2010).

In the tomato- Fol interactions studied here the level of pathogen-restriction correlates with the type of R-protein present: transmembrane or intracellular. The plant lines used, however, are not fully isogenic. So, although the genetics of $R$-gene mediated resistance in these lines is well established (Houterman et al. 2008) and two independent $R$ genes mediating extracellular Avr-recognition were tested (GCR161 with $I$ and E779 with $I-3$ ), we cannot fully exclude that differences in genetic background may have some influence on the extent of Fol colonization in incompatible interactions. We also acknowledge that, although it is likely that differences in the extent of stem colonization correlate with a quantitative differences in the amount of fungus growing inside the stem, we have not determined this.

Assuming that indeed the different $\mathrm{R}$ genes in tomato differ in their efficacy to restrict Fol xylem colonization, we consider that this could be due to different timing, different kind and/or different magnitude of the associated immune responses. The timing of the immune response depends, at least partly, on the moment of Avr-recognition. Avr-recognition by intracellular R-proteins, like I-2, requires translocation of the Avr protein into the host cell after it has been secreted into the apoplast or xylem by the pathogen. Translocation is not required for the transmembrane receptors I and I-3. The requirement of Avr translocation may delay recognition, resulting in a less rapid resistance response. Indeed, when $I-2$ is co-expressed with $A V R 2$ in $N$. benthamiana leaves the resistance response occurs faster if Avr2 is targeted to the cytosol (i.e. when the primary product lacks the signal peptide), rather than to the apoplast (the polypeptide is produced with signal peptide) from which it is subsequently translocated into the cytosol (Houterman et al. 2009). Additionally, $I-2$ is expressed around the vasculature, suggesting that I-2 is activated only after xylem colonization by Fol. For $I$ and $I-3$, expression patterns are unknown, but we found no obvious differences in early colonization patterns between the incompatible interactions tested; restricted stem 
colonization at later time points was observed in all cases. This suggests that also $I$ and $I-3$ mediated resistance is achieved around or close to the vasculature. Either $I$ and $I-3$ detect their respective Avr's earlier than I-2, or the immune response mounted by I and I-3 is quantitatively or qualitatively different than the response following I-2 activation. The known signaling differences between these R-proteins, such as the ability to produce a hypersensitive response (HR) in a heterologous system, or their requirement for an EDS1 homologue (Table 1), do not correlate with the observed differences in fungal restriction. Rather, EDS1-independent signaling correlates with Avr1mediated suppression of resistance. This suppression affects the $E D S 1$-independent $R$-genes $I-2$ and $I-3$, but not the EDS1-dependent I-7 (Gonzalez-Cendales et al. 2016; De Wit 2016). If different $R$-genes mount distinct responses, it would be interesting to test whether simultaneous activation of multiple $R$-genes results in an even further reduced fungal colonization.

Finally, regardless of whether the different $R$-genes mount different immune responses, one of the most elusive questions is still which plant response(s) are critical to restrict fungal growth? We show here that Fol can effectively grow in xylem tissue during an immune response, albeit at a reduced growth rate. In fact, in incompatible Fol-tomato interactions, Fol behaves as an endophyte that quite effectively colonizes its host. This raises a second question: how does the plant tolerate these levels of fungal colonization without developing wilting symptoms?

Acknowledgements This project has received funding from the European Union's Horizon 2020 research and innovation programme under the Marie Skłodowska-Curie grant agreement No 676480. We are greatly indebted to the students and practicum assistants of the Bachelor course 'communication in biological systems' of 2011, 2012, 2013, 2014, 2015, 2016 and 2017 for testing the extent of colonization of resistant and susceptible tomato plants by Fol007.

Compliance with ethical standards There are no potential conflicts of interest, and this research did not involve human participants and/or animals.

Open Access This article is distributed under the terms of the Creative Commons Attribution 4.0 International License (http:// creativecommons.org/licenses/by/4.0/), which permits unrestricted use, distribution, and reproduction in any medium, provided you give appropriate credit to the original author(s) and the source, provide a link to the Creative Commons license, and indicate if changes were made.

\section{References}

Bani, M., Rubiales, D., \& Rispail, N. (2012). A detailed evaluation method to identify sources of quantitative resistance to Fusarium oxysporum f. sp pisi race 2 within a Pisum spp. germplasm collection. Plant Pathology, 61(3), 532-542. https://doi.org/10.1111/j.1365-3059.2011.02537.x.

Buruchara, R. A., \& Camacho, L. (2000). Common bean reaction to fusarium oxysporum $\mathrm{f}$. Sp phaseoli, the cause of severe vascular wilt in Central Africa. Journal of PhytopathologyPhytopathologische Zeitschrift, 148(1), 39-45. https://doi. org/10.1046/J.1439-0434.2000.00457.X.

Catanzariti, A. M., Lim, G. T., \& Jones, D. A. (2015). The tomato I-3 gene: A novel gene for resistance to fusarium wilt disease. [research support, non-U.S. Gov't]. The New Phytologist, 207(1), 106-118. https://doi.org/10.1111/nph.13348.

Catanzariti, A. M., Do, H. T., Bru, P., de Sain, M., Thatcher, L. F., Rep, M., et al. (2017). The tomato I gene for fusarium wilt resistance encodes an atypical leucine-rich repeat receptorlike protein whose function is nevertheless dependent on SOBIR1 and SERK3/BAK1. The Plant Journal, 89(6), 1195-1209. https://doi.org/10.1111/tpj.13458.

De Wit, P. J. (2016). Apoplastic fungal effectors in historic perspective; a personal view. [letter]. The New Phytologist, 212(4), 805-813. https://doi.org/10.1111/nph.14144.

De Wit, P. J., Hofman, A. E., Velthuis, G. C., \& Kuc, J. A. (1985). Isolation and characterization of an elicitor of necrosis isolated from intercellular fluids of compatible interactions of Cladosporium fulvum (Syn. Fulvia fulva) and tomato. Plant Physiology, 77(3), 642-647. https://doi.org/10.1104 /Pp.77.3.642.

Deslandes, L., Pileur, F., Liaubet, L., Camut, S., Can, C., Williams, K., Holub, E., Beynon, J., Arlat, M., \& Marco, Y. (1998). Genetic characterization of RRS1, a recessive locus in Arabidopsis thaliana that confers resistance to the bacterial soilborne pathogen Ralstonia solanacearum. [research support, non-U.S. Gov't]. Molecular Plant-Microbe Interactions, 11(7), 659-667. https://doi.org/10.1094 /MPMI.1998.11.7.659.

Deslandes, L., Olivier, J., Theulieres, F., Hirsch, J., Feng, D. X., Bittner-Eddy, P., Beynon, J., \& Marco, Y. (2002). Resistance to Ralstonia solanacearum in Arabidopsis thaliana is conferred by the recessive RRS1-R gene, a member of a novel family of resistance genes. [research support, non-U.S. Gov't]. Proceedings of the National Academy of Sciences of the United States of America, 99(4), 2404-2409. https://doi. org/10.1073/pnas.032485099.

Di, X., Gomila, J., Ma, L., van den Burg, H. A., \& Takken, F. L. (2016). Uptake of the fusarium effector Avr2 by tomato is not a cell autonomous event. Frontiers in Plant Science, 7, 1915. https://doi.org/10.3389/fpls.2016.01915.

Fradin, E. F., Zhang, Z., Juarez Ayala, J. C., Castroverde, C. D., Nazar, R. N., Robb, J., et al. (2009). Genetic dissection of Verticillium wilt resistance mediated by tomato Ve1. [research support, non-U.S. Gov't]. Plant Physiology, 150(1), 320-332. https://doi.org/10.1104/pp.109.136762.

Garces-Fiallos, F. R., de Borba, M. C., Schmidt, E. C., Bouzon, Z. L., \& Stadnik, M. J. (2017). Delayed upward colonization of xylem vessels is associated with resistance of common bean to fusarium oxysporum f. Sp phaseoli. European Journal of 
Plant Pathology, 149(2), 477-489. https://doi.org/10.1007 /s10658-017-1197-6.

Gonzalez-Cendales, Y., Catanzariti, A. M., Baker, B., McGrath, D. J., \& Jones, D. A. (2016). Identification of I-7 expands the repertoire of genes for resistance to fusarium wilt in tomato to three resistance gene classes. [research support, non-U.S. Gov't]. Molecular Plant Pathology, 17(3), 448-463. https://doi.org/10.1111/mpp.12294.

Hajdukiewicz, P., Svab, Z., \& Maliga, P. (1994). The small, versatile pPZP family of agrobacterium binary vectors for plant transformation. [research support, non-U.S. Gov't]. Plant Molecular Biology, 25(6), 989-994.

Houterman, P. M., Speijer, D., Dekker, H. L., DE Koster, C. G., Cornelissen, B. J., \& Rep, M. (2007). The mixed xylem sap proteome of fusarium oxysporum-infected tomato plants. Molecular Plant Pathology, 8(2), 215-221. https://doi. org/10.1111/j.1364-3703.2007.00384.x.

Houterman, P. M., Cornelissen, B. J., \& Rep, M. (2008). Suppression of plant resistance gene-based immunity by a fungal effector. [research support, non-U.S. Gov't]. PLoS Pathog, 4(5), e1000061. https://doi.org/10.1371/journal. ppat.1000061.

Houterman, P. M., Ma, L., van Ooijen, G., de Vroomen, M. J., Cornelissen, B. J., Takken, F. L., et al. (2009). The effector protein Avr2 of the xylem-colonizing fungus fusarium oxysporum activates the tomato resistance protein I-2 intracellularly. [research support, non-U.S. Gov't]. The Plant Journal, 58(6), 970-978. https://doi.org/10.1111/j.1365-313 X.2009.03838.x.

Huang, C. C., \& Lindhout, P. (1997). Screening for resistance in wild Lycopersicon species to fusarium oxysporum $\mathrm{f} \mathrm{sp}$ lycopersici race 1 and race 2. Euphytica, 93(2), 145-153. https://doi.org/10.1023/A:1002943805229.

Jones, J. D., \& Dangl, J. L. (2006). The plant immune system. [review]. Nature, 444(7117), 323-329. https://doi. org/10.1038/nature05286.

Keen, N. T. (1990). Gene-for-gene complementarity in plantpathogen interactions. Annual Review of Genetics, 24, 447463. https://doi.org/10.1146/Annurev.Ge.24.120190.002311.

Krasikov, V., Dekker, H. L., Rep, M., \& Takken, F. L. (2011). The tomato xylem sap protein XSP10 is required for full susceptibility to fusarium wilt disease. Journal of Experimental Botany, 62(3), 963-973. https://doi.org/10.1093/jxb/erq327.

Lin, F., Xue, S. L., Zhang, Z. Z., Zhang, C. Q., Kong, Z. X., Yao, G. Q., Tian, D. G., Zhu, H. L., Li, C. J., Cao, Y., Wei, J. B., Luo, Q. Y., \& Ma, Z. Q. (2006). Mapping QTL associated with resistance to fusarium head blight in the Nanda2419 $\mathrm{x}$ Wangshuibai population. II: Type I resistance. [research report, non-U.S. Gov't]. Theoretical and Applied Genetics, 112(3), 528-535. https://doi.org/10.1007/s00122-005-0156-3.

Lu, G. Y., Guo, S. G., Zhang, H. Y., Geng, L. H., Martyn, R. D., \& $\mathrm{Xu}, \mathrm{Y}$. (2014). Colonization of fusarium wilt-resistant and susceptible watermelon roots by a green-fluorescent-proteintagged isolate of fusarium oxysporum f.Sp.niveum. Journal of Phytopathology, 162(4), 228-237. https://doi.org/10.1111 /jph.12174.

Mes, J. J., Weststeijn, E. A., Herlaar, F., Lambalk, J. J., Wijbrandi, J., Haring, M. A., et al. (1999). Biological and molecular characterization of fusarium oxysporum $\mathrm{f}$. Sp. lycopersici divides race 1 isolates into separate virulence groups. Phytopathology, 89(2), 156-160. https://doi.org/10.1094 /PHYTO.1999.89.2.156.

Mes, J. J., van Doorn, A. A., Wijbrandi, J., Simons, G., Cornelissen, B. J., \& Haring, M. A. (2000). Expression of the fusarium resistance gene I-2 colocalizes with the site of fungal containment. The Plant Journal, 23(2), 183-193.

Pritsch, C., Muehlbauer, G. J., Bushnell, W. R., Somers, D. A., \& Vance, C. P. (2000). Fungal development and induction of defense response genes during early infection of wheat spikes by fusarium graminearum. Molecular Plant-Microbe Interactions, 13(2), 159-169. https://doi.org/10.1094 /MPMI.2000.13.2.159.

Pruitt, R. N., Schwessinger, B., Joe, A., Thomas, N., Liu, F., Albert, M., Robinson, M. R., Chan, L. J. G., Luu, D. D., Chen, H., Bahar, O., Daudi, A., de Vleesschauwer, D., Caddell, D., Zhang, W., Zhao, X., Li, X., Heazlewood, J. L., Ruan, D., Majumder, D., Chern, M., Kalbacher, H., Midha, S., Patil, P. B., Sonti, R. V., Petzold, C. J., Liu, C. C., Brodbelt, J. S., Felix, G., \& Ronald, P. C. (2015). The rice immune receptor XA21 recognizes a tyrosine-sulfated protein from a gram-negative bacterium. Science Advances, 1(6), e1500245. https://doi.org/10.1126/sciadv.1500245.

Rep, M., Dekker, H. L., Vossen, J. H., de Boer, A. D., Houterman, P. M., Speijer, D., Back, J. W., de Koster, C. G., \& Cornelissen, B. J. (2002). Mass spectrometric identification of isoforms of PR proteins in xylem sap of fungus-infected tomato. [research support, non-U.S. Gov't]. Plant Physiology, 130(2), 904-917. https://doi.org/10.1104/pp.007427.

Rep, M., van der Does, H. C., Meijer, M., van Wijk, R., Houterman, P. M., Dekker, H. L., de Koster, C. G., \& Cornelissen, B. J. C. (2004). A small, cysteine-rich protein secreted by fusarium oxysporum during colonization of $x y-$ lem vessels is required for I-3-mediated resistance in tomato. [research support, non-U.S. Gov't]. Molecular Microbiology, 53(5), 1373-1383. https://doi.org/10.1111/j.13652958.2004.04177.x.

Rep, M., Meijer, M., Houterman, P. M., van der Does, H. C., \& Cornelissen, B. J. (2005). Fusarium oxysporum evades I-3mediated resistance without altering the matching avirulence gene. [research support, non-U.S. Gov't]. Molecular PlantMicrobe Interactions, 18(1), 15-23. https://doi.org/10.1094 /MPMI-18-0015.

Sarfatti, M., Abu-Abied, M., Katan, J., \& Zamir, D. (1991). RFLP mapping of I1, a new locus in tomato conferring resistance against fusarium oxysporum $\mathrm{f}$. Sp. lycopersici race 1 . Theoretical and Applied Genetics, 82(1), 22-26. https://doi. org/10.1007/BF00231273.

Simons, G., Groenendijk, J., Wijbrandi, J., Reijans, M., Groenen, J., Diergaarde, P., et al. (1998). Dissection of the fusarium I2 gene cluster in tomato reveals six homologs and one active gene copy. [research support, non-U.S. Gov't]. Plant Cell, 10(6), 1055-1068.

Takken, F., \& Rep, M. (2010). The arms race between tomato and fusarium oxysporum. [review]. Molecular Plant Pathology, 11(2), 309-314. https://doi.org/10.1111/j.13643703.2009.00605.x.

Takken, F. L., Van Wijk, R., Michielse, C. B., Houterman, P. M., Ram, A. F., \& Cornelissen, B. J. (2004). A one-step method 
to convert vectors into binary vectors suited for agrobacterium-mediated transformation. Current Genetics, 45(4), 242-248. https://doi.org/10.1007/s00294-003-0481-5.

Tchernoff, V. (1965). Methods for screening and for the rapid selection of elms for resistance to Dutch elm disease. Acta Botanica Neerlandica, 14, 409-452. https://doi.org/10.1111 /j.1438-8677.1965.tb00204.x.

van der Does, H. C., Duyvesteijn, R. G., Goltstein, P. M., van Schie, C. C., Manders, E. M., Cornelissen, B. J., et al. (2008). Expression of effector gene SIX1 of fusarium oxysporum requires living plant cells. Fungal Genetics and Biology, 45(9), 1257-1264. https://doi.org/10.1016/j. fgb.2008.06.002.

Wellman, F. L. (1939). A technique for studying host resistance and pathogenicity in tomato fusarium wilt. Phytopathology, 29, 945-956.

Westerdijk, J., Ledeboer, M., \& Went, J. C. (1931). Mededeelingen omtrent gevoeligheidsproeven van iepen voor Graphium ulmi
Schwarz gedurende 1929 en 1930. Tijdschr. over Plantenziekten, 37, 105-110.

Xue, S., Li, G., Jia, H., Xu, F., Lin, F., Tang, M., Wang, Y., An, X., Xu, H., Zhang, L., Kong, Z., \& Ma, Z. (2010). Fine mapping Fhb4, a major QTL conditioning resistance to fusarium infection in bread wheat (Triticum aestivum L.). [research support, non-U.S. Gov't]. Theoretical and Applied Genetics, 121(1), 147-156. https://doi.org/10.1007/s00122-010-1298-5.

Yoshimura, S., Yamanouchi, U., Katayose, Y., Toki, S., Wang, Z. X., Kono, I., Kurata, N., Yano, M., Iwata, N., \& Sasaki, T. (1998). Expression of Xa1, a bacterial blight-resistance gene in rice, is induced by bacterial inoculation. [research support, non-U.S. Gov't]. Proceedings of the National Academy of Sciences of the United States of America, 95(4), 1663-1668.

Zhao, M., Wang, G., Leng, Y., Wanjugi, H., Xi, P., Grosz, M., et al. (2018). Molecular mapping of fusarium head blight resistance in the spring wheat line ND2710. Phytopathology, 108, 972-979. https://doi.org/10.1094/PHYTO-12-17-0392-R. 